\title{
JENIS-JENIS INANG SEBAGAI INDIKATOR KEHADIRAN ANGGREK MACAN IRIAN (Gramatophyllum scriptum Blume.) PADA KAWASAN HUTAN DATARAN RENDAH TAMAN WISATA ALAM GUNUNG MEJA
}

\section{(Types of Host Plant as Indicator Occurrrence of Gramatophyllum scriptum Blume. In the Low-Land Forest of Gunung Meja Natural Tourist Park)}

\author{
Melky Benyamin Panie ${ }^{1}$ Antoni Ungirwalu ${ }^{1 凶}$ dan Jimmy F Wanma ${ }^{1}$ \\ Jurusan Kehutanan, Fakultas Kehutanan Universitas Papua Manokwari, Papua Barat, \\ 98314. Tlp/Fax: +62986211065. \\ ${ }^{\otimes}$ Penulis Korespondensi: Email: a.ungirwalu@unipa.ac.id \\ Diterima: 26 Oct 2017| Disetujui: 30 Nov 2017
}

\begin{abstract}
Abstrak
Tujuan dari penelitian ini adalah untuk mengetahui asosiasi anggrek macan irian (Gramatophyllum scriptum) dengan pohon inangnya serta untuk mengetahui habitat dari anggrek ini pada hutan dataran rendah Taman Wisata Alam Gunung Meja menggunakan metode deskriptif dengan teknik survei dan sensus dengan cara menjelajah plot monitoring Biodiversitas TWA Gunung Meja. Hasil penelitian menunjukan bahwa terdapat 148 jenis pohon dan hanya 2 jenis pohon yang berasosiasi dengan anggrek Grammatophyllum scriptum yaitu Pometia coreacea sebanyak 8 pohon dan Octomeles sumatrana sebanyak 1 pohon dengan diameter rata-rata pohon inang adalah $63,78 \mathrm{~cm}$ dan tinggi rata-rata $38,11 \mathrm{~m}$. Tingkat asosiasi anggrek Grammatophyllum scriptum dengan pohon inang Pometia coreacea adalah sangat erat dan tingkat asosiasi anggrek Grammatophyllum scriptum dengan pohon inang Octomeles sumatrana adalah tidak erat. Matoa (Pometia coreacea) dapat digunakan sebagai bioindikator kehadiran anggrek Grammatophyllum scriptum di hutan alam.
\end{abstract}

Kata kunci: asosiasi, angrek, pohon inang, plot monitoring, TWA gunug meja

\begin{abstract}
This study objective was to notice an association of macan irian orchid species (Gramatophyllum scriptum) with its host plant as well as to denote the habitat of the orchid in the low-land forest of Gunung Meja nature tourist park using descriptive method through survey technique and census by exploration of biodiversity monitoring plot in Gunung Meja. The results showed that there were 148 tree species in which 2 species had the association with Grammatophyllum scriptum namely Pometia coreacea with 8 individuals and Octomeles sumatrana with only 1 individual. The average dimeter of the host tree was $63.78 \mathrm{~cm}$ and the average tree height was $38.11 \mathrm{~cm}$. A very tight association has been shown between Grammatophyllum scriptum and Pometia coreacea as the host, while a weak association has been indicated between Grammatophyllum scriptum with Octomeles sumatrana as the host. There was an indication of Pometia coreacea to be a bioindicator occurrence of the orchid in the natural forest.
\end{abstract}

Keywords: association, orchid, host plant, monitoring plot, Gunung Meja natural tourist park 


\section{PENDAHULUAN}

Indonesia dengan luas daratan 1,9 juta $\mathrm{km}^{2}$ memiliki sumber daya berupa hutan tropis yang memiliki keanekaragaman hayati yang tinggi sehingga dikenal sebagai salah pusat keanekaragaman hayati di dunia. Kekayaan alam tersebut disebabkan karena letak Indonesia yang berada diantara dua biogeografi utama yaitu Indomalaya dan Australasia. Secara ekologi wilayah Indonesia dapat dibagi dalam 7 regional biografi utama yaitu: Sumatera, Jawa, Bali, Kalimatan, Nusatenggara, Maluku dan Papua (Prosseding Kehutanan 1995).

Papua sebagai salah satu pulau terbesar di Indonesia dengan luas hutan \pm 41 juta ha, memiliki kekayaan berupa keanekaragaman biodiversitas flora dan fauna yang sangat tinggi jika dibandingkan dengan daerah-daerah lain di Indonesia. Menurut Johns (1997), jumlah flora di Papua diperkirakan sekitar 20.000 - 25.000 jenis, dengan 1.465 marga dan paling sedikit 142 marga bersifat endemik, dimana $50 \%-90 \%$ merupakan jenis endemic, baik endemik dalam skala terbatas maupun luas. Menurut Muller (2005), Faktor utama yang bertanggung jawab terhadap komposisi dan keanekaragaman flora di Papua adalah geologi, geografi dan iklim.

Sejarah geologi pembentukan pulau Papua yang rumit serta pengaruh ciri fisiografi mengakibatkan Tanah papua memiliki lingkungan habitat dengan zona-zona vegetasi terlengkap di asiapasifik mulai dari daerah pantai hingga alpin. Karena adanya pengaruh adaptasi, mengakibatkan flora Papua memiliki karakter-karakter yang sangat unik, keadaan ini telah menciptakan kekayaan flora yang sangat tinggi di tanah Papua.
Anggrek merupakan kelompok jenis tumbuhan yang banyak dijumpai pada hutan alam tropis di Papua. Terdapat kurang lebih 4.000 jenis anggrek di Papua. Beberapa jenis anggrek yang tergolong jenis flora langka menurut Lembaga Ilmu Pengatahuan Indonesia Tahun 2000, salah satunya adalah anggrek macan (Grammatophyllum scriptum).

Tujuan penelitian ini adalah untuk mengetahui asosiasi anggrek macan irian (Gramatophyllum scriptum) dengan pohon inangnya serta untuk mengetahui habitat dari anggrek ini pada hutan dataran rendah TWA Gunung Meja.

\section{METODE PENELITIAN}

Penelitian ini dilaksanakan selama \pm 2 minggu yaitu dari tanggal 17 Juni sampai dengan 27 Juni tahun 2013. Lokasi atau tempat dilaksanakannya penelitian ini adalah plot monitoring biodiversitas hutan Taman Wisata Alam Gunung Meja Kabupaten Manokwari. Metode yang digunakan dalam penelitian ini adalah metode deskriptif dengan teknik survei dan sensus dengan cara menjelajah plot monitoring Biodiversitas.

\section{Variabel dan Data Pengamatan}

Variabel yang diamati adalah asosiasi antara anggrek macan Irian dengan pohon inang meliputi kehadiran jenis anggrek macan Irian Gramatophyllum scriptum Blume dan pohon inang serta pohon lain yang dijumpai dalam jalur pengamatan. Data pengamatan yang diamati dalam penelitian ini terdiri dari data utama dan data penunjang.

I. Data utama terdiri dari:
1. Anggrek macan (Grammatophyllum Irian Blume) 
- Jumlah anggrek macan Irian (Grammatophyllum scriptum Blume) yang berasosiasi dengan pohon inang dan letak pada batang, cabang atau ranting.

- Tinggi Anggrek macan Irian (Grammatophyllum scriptum Blume) pada pohon inang dari permukaan tanah.

2. Pohon Inang

- Jenis dan jumlah pohon inang yang ditumbuhi anggrek macan Irian (Grammatophyllum scriptum Blume).

- Jenis dan jumlah pohon inang yang tidak ditumbuhi anggrek macan Irian (Grammatophyllum scriptum Blume).

- Pohon inang lain yang ditumbuhi anggrek macan Irian (Grammatophyllum scriptum Blume).

- Diameter $(\mathrm{cm})$ dan Tinggi pohon (m).

II. Data penunjang terdiri dari :

Suhu, kelembaban, keadaan tanah, ketinggian tempat dpl dan topografi pada lokasi penelitian.

\section{Pengumpulan Data}

Pengamatan terhadap anggrek macan Irian (Grammatophyllum scriptum Blume) dan pohon inang dilakukan dengan melakukan penjelajahan (sensus) mengelilingi plot monitoring biodiversitas flora Taman Wisata Alam Gunung Meja.

\section{Pengolahan Data}

Pengolahan data akan dilakukan dengan pendekatan Indeks Asosiasi (IA) berdasarkan kehadiran $(\mathrm{P}=$ presence $)$ dengan menggunakan rumus menurut Mueller-Dombois dan Ellenberg (1974) dalam Baratawinata (2001) yang dimodifikasi sesuai dengan tujuan penelitian.

$$
\mathrm{IAp}=\frac{\mathrm{C}}{\mathrm{A}+\mathrm{B}+\mathrm{C}} \times 100(\%)
$$

Dimana :

IAP $=$ Indeks asosiasi berdasarkan kehadiran jenis

A $=$ Banyaknya pohon yang tidak ditumbuhi anggrek macan

$\mathrm{B}=$ Banyaknya pohon inang lain yang ditumbuhi anggrek macan

$\mathrm{C}=$ Jumlah pohon inang yang ditumbuhi oleh anggrek macan

Penentuan tingkat asosiasi yang digunakan adalah dihitung setelah nilai dari perhitungan indeks asosiasi indeks asosiasi berdasarkan kehadiran jenis sebagai berikut:

Nilai Maximum (IAP) - Nilai Minimum IAP

$$
\text { Banyaknya Kelas }
$$

Dengan pembagian kelas (tabel 1) sebagai berikut:

Tabel 1. Pembagian kelas asosiasi berdasarkan kehadiran

\begin{tabular}{lccc}
\hline No. & Kelas & Kriteria & Nilai \\
& & & \\
\hline 1. & I & Tidak erat & $0-25$ \\
2. & II & Kurang erat & $26-50$ \\
3. & III & Erat & $51-75$ \\
4. & IV & Sangat erat & $76-100$ \\
\hline
\end{tabular}

\section{Analisis Data}

Data yang telah dikumpulkan akan diolah secara tabulasi dan dianalisis secara deskriptif. Data disajikan dalam bentuk tabel dan gambar. 


\section{HASIL DAN PEMBAHASAN}

\section{Jenis Pohon Pada Lokasi Penelitian}

Hasil penelitian diketahui pada plot monitoring biodiversitas flora TWA Gunung, Meja memliki 148 jenis pohon yang tergolong dalam 34 famili dengan jumlah total individu sebanyak 1.196 pohon. Famili yang dominan adalah Euphorbiaceae dengan 11 marga, marga dominan adalah Ficus dengan 7 jenis, sedangkan untuk jenis yang paling dominan adalah Pometia coreacea Radlk dengan jumlah 96 individu.

Indeks keanekaragaman jenis atau indeks Shannon-Wienners (Ludwig and Reynolds 1988) untuk tingkat pohon pada kawasan ini adalah 4,227 atau tergolong sangat tinggi. Hal ini menunjukan bahwa plot monitoring biodiversitas flora pada kawasan hutan dataran rendah TWA Gunung Meja memiliki keanekaragaman hayati yang cukup tinggi.

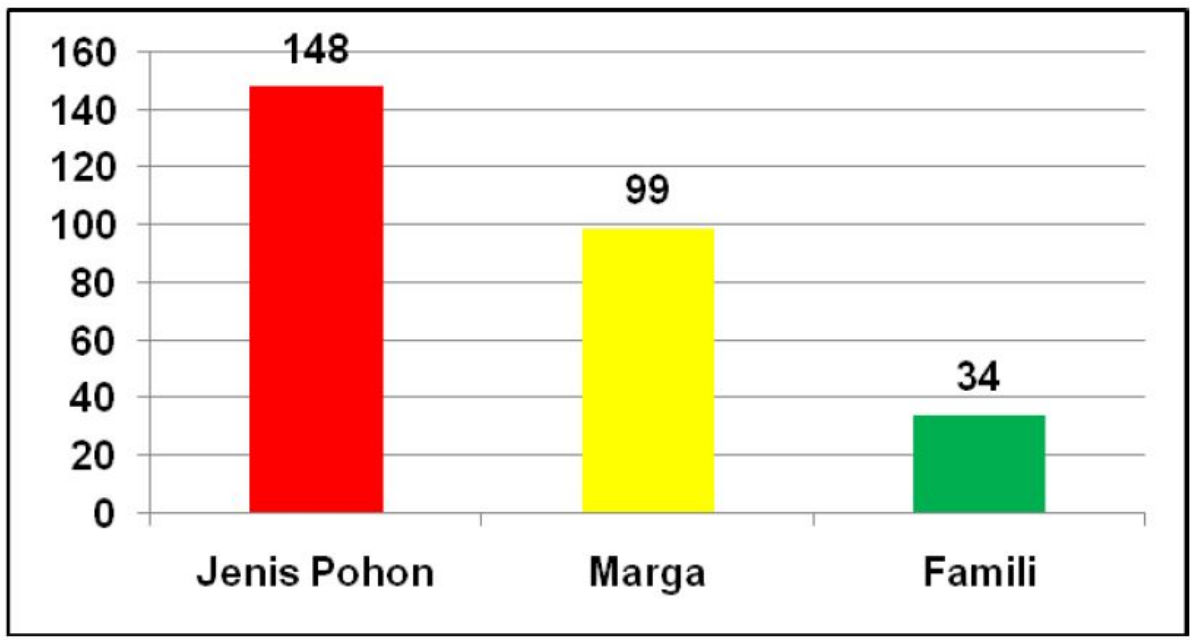

Gambar 1. Perbandingan jumlah jenis, marga dan famili pohon pada plot monitoring flora TWA Gunung Meja.

Data jumlah jenis dan famili pohon secara lengkap disajikan pada lampiran 3. Dari data tersebut dapat disimpulkan bahwa tidak seharusnya famili yang dominan mempunyai marga yang dominan. Demikian pula marga yang dominan tidak harus diikuti oleh spesies yang dominan. Komposisi jenis 10 pohon dominan pada plot monitoring biodiversitas flora Taman Wisata Alam Gunung Meja Kabupaten Manokwari secara lengkap dapat dilihat pada tabel 2. Pohon yang paling dominan dan menjadi penciri utama di lokasi penelitian adalah
Pometia coreacea Radlk (tabel 2), jenis ini dominan karena jumlah individu dan penyebaran yang cukup merata serta ratarata pertumbuhan diameter yang baik. Jenis dominan lainnya berturut-turut adalah Pometia pinnata dan Alstonia scholaris. Jenis Pometia pinnata menjadi pohon dominan kedua disebabkan karena jumlah individu yang banyak dan penyebarannya sangat merata di lokasi penelitian namun memiliki rata-rata pertumbuhan diameter yang masih rendah. Sedangkan jenis Alstonia scholaris menjadi pohon dominan ketiga 
karena memiliki rata-rata pertumbuhan diameter yang lebih baik dan jumlah individu serta penyebarannya yang cukup merata di lokasi penelitian.

Tabel 2. Komposisi jenis 10 pohon dominan pada lokasi penelitian

\begin{tabular}{lllllllll}
\hline No. & Nama jenis & K & $\begin{array}{l}\text { KR } \\
(\%)\end{array}$ & F & $\begin{array}{l}\text { FR } \\
(\%)\end{array}$ & D & $\begin{array}{l}\text { DR } \\
(\%)\end{array}$ & $\begin{array}{l}\text { INP } \\
(\%)\end{array}$ \\
\hline 1. & Pometia coreacea Radlk. & 3,84 & 8,03 & 0,40 & 6,35 & 0,87 & 15,01 & 29,39 \\
2. & Pometia pinnata & 4,32 & 9,03 & 0,48 & 7,62 & 0,37 & 6,34 & 22,99 \\
3. & Alstonia scholaris & 2,20 & 4,60 & 0,27 & 4,20 & 0,40 & 6,96 & 15,76 \\
4. & Pimelodendron amboinicum & 1,88 & 3,93 & 0,24 & 3,81 & 0,13 & 2,27 & 10,01 \\
5. & Pterygota horsfieldia & 1,20 & 2,51 & 0,17 & 2,64 & 0,22 & 3,82 & 8,97 \\
6. & Haplolobus lanceolatus & 1,48 & 3,09 & 0,19 & 2,93 & 0,12 & 2,08 & 8,10 \\
7. & Euodia elleryana & 1,36 & 2,84 & 0,16 & 2,54 & 0,12 & 2,15 & 7,54 \\
8. & Artocarpus fretissi & 1,00 & 2,09 & 0,12 & 1,86 & 0,16 & 2,81 & 6,76 \\
9. & Streblus elongata & 1,04 & 2,17 & 0,14 & 2,25 & 0,10 & 1,79 & 6,21 \\
10. & Spondias cytherea & 0,60 & 1,25 & 0,09 & 1,37 & 0,16 & 2,83 & 5,46 \\
\hline
\end{tabular}

Ketereangan : $\mathrm{K}=$ Kerapatan, $\mathrm{KR}=$ Kerapatan Relatif, $\mathrm{F}=$ Frekwensi, $\mathrm{FR}=$ Frekwensi Relatif, $\mathrm{D}=$ Dominansi, $\mathrm{DR}=$ Dominansi Relatif dan INP=Indeks Nilai Penting

Menurut Lekitoo (2011), secara umum penyebaran jenis Pometia coreacea Radlk dan Pometia pinnata cukup merata di lokasi penelitian plot monitoring flora TWA Gunung Meja disebabkan karena kedua jenis ini memiliki buah yang dikonsumsi oleh semua satwa liar seperti burung, kelelawar, kus-kus dan lainnya, sehingga pemencaran biji kedua jenis tersebut merata pada lokasi penelitian.

\section{Jenis Pohon Inang Yang Ditumbuhi}

Anggrek Grammatophyllum scriptum

Blume

Dari hasil penelitian diketahui bahwa jenis pohon inang yang ditumbuhi anggrek Grammatophyllum scriptum
Blume sebanyak 9 pohon atau $0,67 \%$. Famili yang dominan adalah Sapindaceae dengan total individu 8, marga dominan adalah Pometia dengan 1 jenis, sedangkan jenis yang dominan adalah Pometia coreacea Radlk dengan 8 individu. Hal ini sesuai dengan pendapat Richard (1975) yang menyatakan bahwa umumnya di daerah tropis pohon-pohon dalam hutan ditumbuhi epifit yang hidupnya menempel pada pohon inang, contohnya anggrek, paku-pakuan. Jenisjenis pohon inang yang ditumbuhi oleh anggrek Grammatophyllum scriptum Blume secara lengkap dapat dilihat pada tabel 3.

Tabel 3. Jumlah pohon inang yang ditumbuhi anggrek Grammatophyllum scriptum Blume

\begin{tabular}{llcccc}
\hline No. & Jenis pohon inang & $\begin{array}{c}\text { N pohon inang } \\
\text { terdapat anggrek }\end{array}$ & \multicolumn{3}{c}{ Kisaran diameter } \\
\cline { 3 - 6 } & & 8 & 1 & 3 & 4 \\
\hline 1. & Pometia coreaceae Radlk. & 1 & & & 1 \\
2. & \begin{tabular}{c} 
Octomeles sumatrana Miq. \\
\multicolumn{2}{l}{ Jumlah }
\end{tabular} & 9 & 1 & 3 & 5 \\
\hline
\end{tabular}


Dari tabel 3 nampak bahwa terdapat 2 jenis pohon inang yang ditumbuhi anggrek Grammatophyllum scriptum Blume. Jenis yang paling banyak ditumbuhi anggrek Grammatophyllum scriptum Blume adalah Pometia coreacea Radlk ( 8 pohon atau sebanyak $88,89 \%$ ) diikuti Octomeles sumatrana Miq (1 pohon atau 11,11\%). Kenyataan di lapangan menunjukan rata-rata pohon inang yang terdapat anggrek Grammatophyllum scriptum Blume, umumnya merupakan pohon berukuran besar yaitu berdiameter $43-85 \mathrm{~cm}$ dengan tinggi 29-46 m, sehingga cukup mendapat cahaya matahari. Adanya kecenderungan (trend) pohon matoa sebagai inang anggrek Grammatophyllum scriptum Blume karena adanya sifat alami karakter anggrek tersebut, dimana anggrek ini umumnya berukuran besar (anggrek raksasa) sehingga memiliki berat yang dapat mencapai 1-2 ton. Kecenderungan tersebut mengakibatkan dalam distribusi dan pemencaran bijinya, anggrek ini secara alami akan beradaptasi dengan pohon inangnya sesuai dengan karakternya yaitu pohon inang tersebut harus kuat sehingga mampu menahan keberadaan jenis anggrek tersebut di alam dalam jangka waktu tertentu. Hal ini dapat dilihat pada tabel 2 yang menunjukkan bahwa anggrek Grammatophyllum scriptum Blume paling banyak tumbuh pada pohon yang memiliki diameter diatas $40 \mathrm{~cm}$. Hal ini didukung oleh pendapat Jhons (1997) dan Lekitoo et al. (2008), yang menyatakan bahwa pohon-pohon inang anggrek Grammatophyllum scriptum Blume seperti yang ditampakkan pada tabel 2 merupakan pohon berukuran besar atau raksasa yang umumnya tumbuh tersebar pada hutan dataran rendah di Papua.

\section{Jumlah Pohon Inang Yang Tidak Ditumbuhi Anggrek Grammatophyllum scriptum Blume}

Jumlah pohon inang yang tidak ditumbuhi anggrek Grammatophyllum scriptum Blume sebanyak 92 pohon. Jumlah pohon inang yang tidak ditumbuhi anggrek Grammatophyllum scriptum Blume disajikan pada tabel 4.

Tabel 4. Jumlah pohon inang yang tidak ditumbuhi anggrek Grammatophyllum scriptum Blume

\begin{tabular}{lcc}
\hline No. & Jenis pohon & $\begin{array}{c}\text { Jumlah pohon inang } \\
\text { tidak terdapat anggrek }\end{array}$ \\
\hline 1. & Pometia coreaceae Radlk. & 88 \\
2. & Octomeles sumatrana Miq. & 4 \\
& Jumlah & 92 \\
\hline
\end{tabular}

Tabel 4 menunjukkan bahwa jumlah pohon inang yang tidak ditumbuhi anggrek Grammatophyllum scriptum Blume terbanyak adalah Pometia coreacea Radlk (88 pohon). Hal ini disebabkan karena adanya distribusi dan penyebaran anggrek yang tidak merata sehingga kesempatan penyebaran anggrek ini secara alami pun memiliki kecenderungan tidak merata pada lokasi penelitian. Anggrek sebagai tumbuhan umumnya memiliki strategi dalam proses regenerasi dan penyebaran jenisnya, namun faktor alam (kondisi ekologi) tetap merupakan faktor utama penentu bagi proses regenarasi tumbuhan secara alami. Proses seleksi alam dalam hal regenerasi dan distribusi tumbuhan anggrek tersebut 
dikenal dengan seleksi $r$, dimana pada saat awal populasi besar namun pada saat akhir populasi tersebut akan cenderung mengecil atau cenderung berbentuk pyramid (Ewusie 1990).

\section{Letak Anggrek Grammatophyllum scriptum Blume Pada Pohon Inang}

Letak anggrek Grammatophyllum scriptum Blume pada pohon inang umumnya terdapat pada batang dan cabang dan ranting. Letak anggrek
Grammatophyllum scriptum Blume secara lengkap disajikan pada tabel 5. Dari tabel 5 nampak bahwa jumlah anggrek Grammatophyllum scriptum Blume yang terdapat pada cabang pohon inang berjumlah $7(77,78 \%)$ dan yang terdapat pada batang berjumlah 2 $(22,22 \%)$. Hal ini menunjukan bahwa anggrek Grammatophyllum scriptum Blume membutuhkan cahaya matahari yang cukup bagi pertumbuhannya.

Tabel 5. Letak anggrek Grammatophyllum scriptum Blume pada pohon inang

\begin{tabular}{llccc}
\hline No. & Jenis Pohon & \multicolumn{2}{c}{ Letak } & Jumlah \\
\cline { 3 - 4 } & & Batang & Cabang & \\
\hline 1. & Pometia coreaceae Raldk. & 2 & 6 & 8 \\
2. & Octomeles sumatrana Miq. & - & 1 & 1 \\
& $\quad$ Jumlah & 2 & 7 & 9 \\
\hline
\end{tabular}

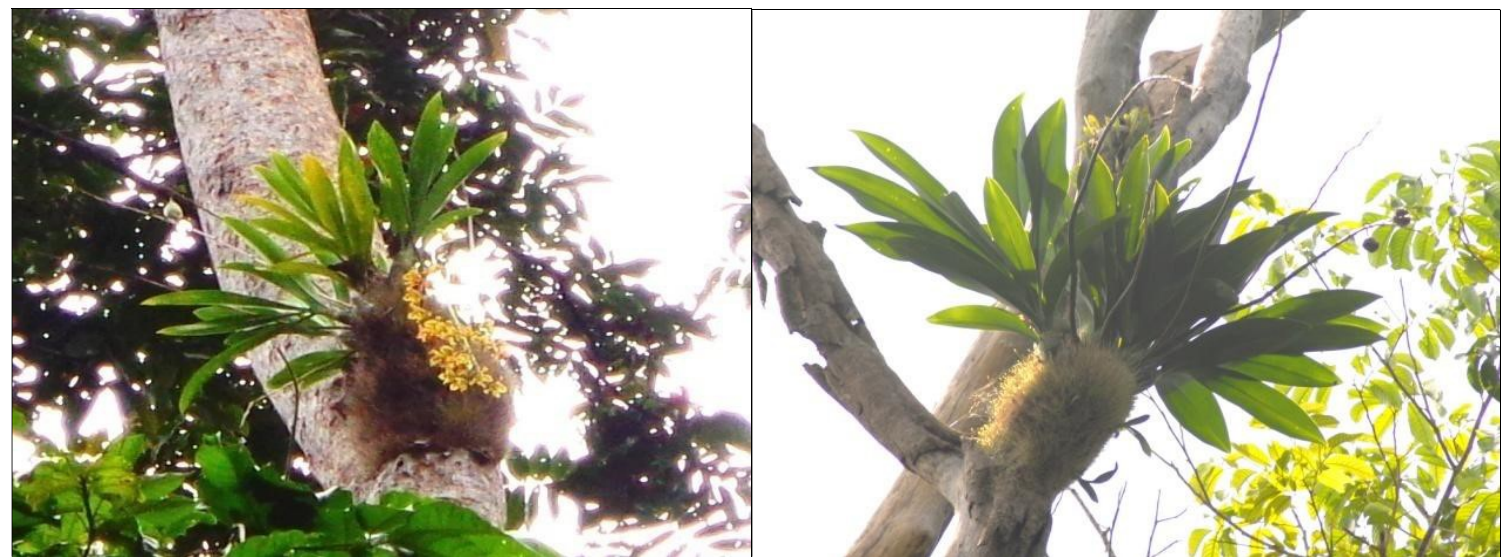

Gambar 2. (sisi kiri) Anggrek Grammatophyllum scriptum Blume yang tumbuh pada batang Pometia coreacea Radlk; (sisi kanan) Anggrek Grammatophyllum scriptum Blume yang tumbuh pada cabang Pometia coreacea Radlk.

Hasil penelitian menunjukan bahwa jumlah anggrek yang terdapat pada cabang lebih banyak jika dibandingkan dengan yang terdapat pada batang. Hal ini disebabkan karena cabang lebih banyak mendapat cahaya matahari dari pada batang dan juga pada cabang banyak dikunjungi oleh burung yang merupakan salah satu faktor penyebar anggrek itu sendiri. Sedangkan pada batang karekter morfologi dari inang yang kasar yang dapat menahan benih dari hempasan angin dan air hujan sehingga benih dapat tumbuh. Umumnya anggrek yang tumbuh pada batang dijumpai pada pohon-pohon yang mempunyai banyak liana, hal ini disebabkan karena pemencaran biji anggrek ini oleh burung, serangga dan 
angin tertahan oleh liana yang membelit atau menggantung pada pohon sehingga akhirnya benih anggrek tersebut dapat tumbuh dan karena kurangnya persaingan mengakibatkan anggrek tersebut dapat tumbuh dengan baik sampai mencapai tingkat dewasa.

\section{Asosiasi Anggrek Grammatophyllum scriptum Blume Dengan Pohon Inang}

Asosiasi antara angorek

Grammatophyllum scriptum Blume dengan pohon inang ditentukan dengan persen indeks asosiasi (IAP) berdasarkan kehadiran atau ketidakhadiran spesies dengan menggunakan perhitungan nilai indeks kesamaan Jaccard. Hasil perhitungan IAP dari anggrek Grammatophyllum scriptum Blume dengan pohon inang serta kriteria tingkat asosiasi (keeratan hubungan) disajikan pada tabel 6. Dari tabel 6, dapat dibuat kriteria tingkat asosiasi (hubungan keeratan) antar spesies, dengan perhitungan sebagai berikut: $8,247-1,031$ : 4=7,216: $\quad 4=1,804$. Anggrek Grammatophyllum scriptum Blume merupakan anggrek epifit yang menempel dan tumbuh pada pohon untuk mendapat sinar matahari dan air. Sebagai tumbuhan epifit, anggrek ini tidak tergantung pada bahan makanan yang berasal dari pohon inangnya, karena mendapatkan unsur hara dari mineral-mineral yang terbawa oleh udara, air hujan atau aliran batang dan cabang pohon inang, serta bagian kulit pohon yang terkelupas.

Tabel 6. Asosiasi (keeratan hubungan) antara pohon inang dengan anggrek Grammatophyllum scriptum Blume

\begin{tabular}{llcc}
\hline No. & Jenis pohon inang & $\begin{array}{c}\text { IAp } \\
(\%)\end{array}$ & Tingkat asosiasi \\
\hline 1. & Pometia coreacea Raldk. & 8.247 & Sangat erat \\
2. & Octomeles sumatrana Miq. & 1.031 & Tidak erat \\
\hline
\end{tabular}

Tabel 7. Tingkat asosiasi keeratan hubungan antar anggrek dan pohon inang

Kelas Interval Kriteria

\begin{tabular}{ccc}
\hline I & $1,031-2,835$ & Tidak erat \\
II & $2,835-4.639$ & Kurang erat \\
III & $4,639-6,443$ & Erat \\
IV & $6,443-8,247$ & Sangat erat \\
\hline
\end{tabular}

Disamping itu sebagai tumbuhan epifit, Grammatophyllum scriptum Blume mampu melakukan fotosintesis untuk mendapatkan makanan bagi pertumbuhannya, sehingga anggrek ini bukan bersifat parasit yang umumnya merugikan karena mengambil makanan dari pohon inangnya (Indriyanto 2005).
Kurangnya anggrek Grammatophyllum scriptum Blume yang ditemukan pada lokasi penelitian diduga disebabkan oleh perburuan anggrek yang dilakukan secara besar-besaran oleh masyarakat di sekitar kawasan hutan TWA Gunung Meja pada Tahun 1987 dan pemanfaatan hasil hutan (Leppe dan Tokede 2005). Secara langsung telah merusak habitat baik 
hewan maupun tumbuhan termasuk anggrek Grammatophyllum scriptum Blume yang terdapat pada lokasi penelitian sehingga keberadaanya semakin berkurang sejalan dengan bertambahnya waktu. Hal ini dikhawatirkan akan menyebabkan kepunahan secara ekologi anggrek ini pada kawasan TWA Gunung Meja Kabupaten Manokwari.

Berdasarkan tabel 5 diketahui bahwa pohon Octomeles sumatrana Miq memiliki keeratan asosiasi yang rendah dengan anggrek. Namun sebaliknya jenis pohon inang Pometia coreacea Radlk mempunyai tingkat asosiasi tinggi dengan anggrek Grammatophyllum scriptum Blume. Hal ini disebabkan karena Pometia coreacea Radlk memiliki karakter morfologi yaitu kulit batang yang kasar dan agak berlekuk serta kuat sehingga mampu menahan benih dari hempasan air hujan dan angin serta menahan anggrek jika dewasa, memiliki tutupan tajuk rindang tetapi percabangan yang banyak sehingga memungkinkan peneriman cahaya matahari yang cukup bagi pertumbuhan anggrek serta menciptakan suhu yang dibutuhkan oleh anggrek Grammatophyllum scriptum Blume, namun jika dilihat dari tabel diatas tingkat keeratan pohon Pometia coreacea Radlk hanya mencapai $8 \%$ walaupun demikian Pometia coreacea Radlk yang paling tertinggi.

Hasil penelitian juga menunjukan bahwa pohon inang yang terdapat anggrek Grammatophyllum scriptum Blume bervariasi dalam diameter dan tingginya dan umumnya menempati strata pertama (dominan) dari lapisan tajuk teratas. Khusus untuk pohon inang matoa (Pometia coreacea Radlk) yang paling banyak ditemukan jenis anggrek ini, tinggi rata-rata 38,11 meter dengan diameter rata-rata mencapai $63,78 \mathrm{~cm}$ sehingga memungkinkan untuk penerimaan cahaya matahari bagi anggrek Menurut Gunawan (2004), anggrek membutuhkan intensitas cahaya 1.000 2.000 footcandle yang pada umumnya antara 15\%-30\% cahaya matahari penuh, sedangkan untuk suhu dan kelembaban pengamatan dilakukan pada saat panas dan hujan $25{ }^{\circ} \mathrm{C} \quad-32 \quad{ }^{\circ} \mathrm{C}$ dengan kelembaban $\quad 70 \%-95 \% \quad$ Selanjutnya menurut Darmono (2007), anggrek yang tumbuh dan hidup di dataran rendah suhu malam berkisar antara $21{ }^{\circ} \mathrm{C}-27{ }^{\circ} \mathrm{C}$ dan suhu siang $27{ }^{\circ} \mathrm{C}-32^{\circ} \mathrm{C}$, bila suhu udara lebih dari $35^{\circ} \mathrm{C}$, tanaman menjadi terbakar dan akhirnya mati, kebutuhan akan setiap anggrek berbeda-beda bergantung jenis, umur dan kondisi lingkungan.

Hal ini mengindikasikan bahwa jenis pohon inang Pometia coreacea Radlk merupakan jenis yang lebih cocok bagi pertumbuhan anggrek Grammatophyllum scriptum Blume. Jika dibandingkan dengan hasil penelitian Ungirwalu (2003) untuk jenis anggrek Grammatophyllum speciosum pada kawasan hutan koridor Cagar Alam Pegunungan Tamrauw Utara dan Suaka Margasatwa Jamursbamedi diketahui bahwa jenis anggrek Grammatophyllum speciosum pada kawasan tersebut tumbuh pada pohon inang Pometia pinnata, Intsia pelembanica dan Palaquium amboinensis, maka jumlah jenis pohon inang anggrek Grammatophyllum scriptum Blume pada hutan Plot Monitoring Biodiversitas Flora TWA Gunung Meja tergolong rendah. 


\section{DAFTAR PUSTAKA}

Bratawinata AA. 2001. Ekologi hutan hujan tropis dan metoda analisis hutan. Departemen Pendidikan Nasional Direktorat Jendral Pendidikan Tinggi Badan Kerja Sama Perguruan Tinggi Negeri Indonesia Timur (BKS- PTN dan - INTIM). Cox, George. W. 1972. Labpratory Manual of General Ecology. Wim. C. Brown Company Publisher. America.

Darmono WD. 2007. Bertanam anggrek, Penebar Swadaya. Jakarta.

Ewusie JY. 1990. Pengantar ekologi tropika. ITB. Bandung.

Indriyanto. 2005. Ekologi hutan. PT. Bumi Aksara. Jakarta.

Johns RJ. 1997. Background papers for the study of the flora and vegetation of the N. E. Kepala Burung, Irian Jaya, Indonesia. Royal Botanic Gardens, Kew.

Lekitoo K, Remetwa H, Matani OPM dan Heatubun CD. 2008. Keanekaragaman flora Taman Wisata Alam Gunung Meja Papua Barat (jenis-jenis pohonbagian 1). Balai Penelitian Kehutanan Manokwari.

Lekitoo K. 2011. Keanekaragaman jenis dan pola komunitas pada plot monitoring biodiversitas flora Taman Wisata Alam Gunung Meja Kabupaten Manokwari. [Tesis] Fakultas Kehutanan Universitas Gadjah Mada (tidak diterbitkan).

Leppe D dan MJ Tokede. 2005. Potensi biofisik Taman Wisata Alam Gunung Meja. Balai Penelitian Kehutanan. Manokwari.

Ludwig JA and JF Reynolds. 1988. Statistical ecology. John Wiley and Sons, New York.

Muller K. 2005. Keanekeragaman hayati Tanah Papua. Universitas Negeri Papua dan Dinas Pendidikan dan Pengajaran Provinsi Papua.

Prosseding Kehutanan 1995. Seminar kehutanan indonesia mahasiswa V. Fakultas Pertanian Universitas Negeri Cenderawasih Manokwari Irian Jaya 22-26 November 1995.

Richard PW. 1975. The tropical rain forest. An Ecological Study. Canbridge Univ. Press. Canbridge.

Ungirwallu A. 2003. Jenis anggrek pada koridor Kawasan Cagar Alam Pegunungan Tamrau Utara dan Suaka Margasatwa Jamursbamedi. [Skripsi] Fakultas Kehutanan Universitas Papua (tidak diterbitkan). 